\title{
THE EFFECTS OF REFERENTIAL QUESTIONS IN THE EFL CLASSROOM
}

The article deals with complexity and importance of asking questions in the foreign language classroom. Since questions are one of the most essential teaching tools, teachers use them quite frequently during their lessons. The importance of referential questions, which are often referred to as "genuine or real" questions, lies in the fact that they have highly positive influence on the learning process. The qualitative study reported here shows that the impact of referential questions on university students can be characterised as constructive (i.e. effective and creative), leading to constructive conversation in the language seminars.

\section{Introduction}

Questions, and of course, answers create an inevitable part of the usual human use of any language - native, as well as foreign. There are different questions asked for different reasons. Following the Webster's College Dictionary definition of a question we find out that it is a sentence in an interrogative form addressed to someone in order to get information in reply. Thus, it seems that the most natural reason for asking questions is to find some unknown information. In non-educational settings, people rarely ask questions to which they already have answers. It would be at least unnatural if someone asks you: "What's the time?" You answer, e.g.: "It's twelve o'clock." Then the questioner says: "Fine, well done, thank you." This is an example of a typical question-answer interaction in which the teacher checks whether the subject matter, time, has been understood by a learner. Thus, it is evident that asking questions in educational settings, especially in foreign language teaching is completely different from the real-life situations.

\section{Questions in the EFL Classroom}

In any language classroom, questions and answers are a very important part of the technique of teaching, as well as a way to improve learners' use of language. According to Brown ([1], 2001) appropriate questioning can fulfill a number of different functions: teacher questions give students the impetus and opportunity to produce language comfortably without having to risk initiating language themselves; teacher questions can serve to initiate a chain reaction of student interaction among themselves; teacher questions give the instructor immediate feedback about student comprehension; teacher questions provide students with opportunities to find out what they think by hearing what they say. Obviously, teachers have to ask a lot of questions in their lessons and learners get used to answering. Each question that is asked in the lesson can be seen as a mini-learning task as well as a necessary stepping stone to foreign language communication. For this reason, the type of question teachers ask heavily impacts the learning process.

Teachers' questions can be categorized in many ways, therefore different taxonomies have been developed. Long and Sato ([2], 1983) in their study of classroom discourse modified one of the first taxonomies proposed by Kearsley and grouped the teachers' questions into "ECHOIC" (consisting of comprehension checks, clarification requests, and confirmation checks) and "EPISTEMIC" (referential, display, expressive, and rhetorical questions). Out of the seven sub-categories of Long and Sato's taxonomy, display (e.g. What's the opposite of "up" in English?) and referential questions (e.g. Why didn't you do your homework?) as opposing ones in their nature, have been the most frequently investigated and discussed by researchers. However, Pica ([3], 1999) points out that both referential and display questions can be further divided into the open and closed type. Therefore, within the referential/display distinction there are four types of questions:

1. Open referential questions (e.g. Can you tell me how to make chocolate chip muffins?)

2. Closed referential questions (e.g. What's your name?)

3. Open display questions (e.g. Can you summarize five ways to get to the airport?)

4. Closed display questions (e.g. What's the opposite of "up" in English?)

\section{Referential Questions}

Referential questions are questions to which the response is not known by the teacher. They are often referred to as "genuine or real" questions. Thus, these questions meet the natural reason for asking which is to find out some unknown information in reply. Since the questioner does not know the answer to the question, there is a genuine exchange of information. The focus should be on what is said, not on how it is said. Typical examples of class-

\footnotetext{
* Martina Siposova

Department of English Language and Literature, Faculty of Science, University of Zilina, Slovakia, E-mail: martina.siposova@fpv.uniza.sk
} 
room referential questions: "Have you got a brother or sister? What is your mother's/ father's job? Have you been on holiday abroad? Why do/ don't you like...? What's your favourite ...? What did you do over the weekend? What do you think about...?" The answers to these questions are usually difficult to predict as they refer to personal details, experiences, attitudes, opinions and so on. They demand more than the respondent's knowledge of learned facts, and they give the opportunity for a more extended answer by requiring a wider range of linguistic resources. However, it should be noted that referential questions can also be closed and often answered with one word only (e.g. "Have you been on holiday abroad?").

The importance of the use of referential questions has been analyzed and discussed by many researchers. Brock's research revealed ([4], 1986) that the use of referential questions increased the amount of learners' output. Learners' responses to referential questions were on average more than twice as long and more than twice as syntactically complex as their responses to display questions. Moreover, the learners used a far greater number of connective (e.g. and, because, yet, so) to make explicit the links between the propositions they expressed. They also took a significantly greater number of speaking turns. Obviously, referential questions foster the growth of speaking students do in the classroom and they enable students to use the target language meaningfully. Lynch ([5], 1996) introduces three reasons for asking referential questions in classrooms. The first reason for including these "real" questions is quantitative, which corresponds with Brock's research, i.e. learners tend to give longer and more complex and authentic responses. Another is qualitative, i.e. learners in classrooms cannot only be passive responders to teacher's questions; they should also practice taking the initiative in speaking. Thirdly, there is a risk that if teachers mostly use questions to test students' knowledge, it can discourage students from wanting to answer, especially when the teacher insists on answers in full sentences and penalizes for mistakes. Undoubtedly, teachers need to realize and view the whole complexity and potentiality of referential questions before asking them in the EFL classroom.

\section{Design of the study}

The qualitative study reported here shows the impact of teacher's referential questions on the first year university students, aged 19-20, in English language seminar classrooms in November - December 2006. The study was divided into two parts: observation and personal interviews. During the observation of four English language seminars, four students were selected on the basis of their participation in the classroom. Two students (one male and one female), were considered as the most active and enthusiastic about responding to teacher's referential questions, and two students (one male and one female), were considered to be non-active, passive and not willing to respond to questions or take part in the conversation. Having explained the subject matter of referential questions to the students, the personal interviews were carried out with the students. The 25-minute long interviews were taped- recorded to be transcribed and coded on the basis of application of the grounded theory methodology.

\section{Method of the study}

With regard to the methodology of the grounded theory, which is viewed (Pandit, [6]) as the inductive discovery of theory grounded in systematically analysed data, data from the interviews are analysed using the potentials of open, axial and selective coding. Initially, open coding fractures the data into concepts and categories, axial coding then puts the data back together in new ways by making connections between a category and its sub-categories, and finally, through selective coding the categories are integrated to form the initial theoretical framework. A story line is either generated or made explicit. A story is simply a descriptive narrative about the central phenomenon of study and the story line is the conceptualisation of this story (abstracting). When analysed, the story line becomes the core category and subsidiary categories are related to the core category according to the paradigm model, the basic purpose of which is to enable the researcher to think systematically about the data and relate them in complex ways.

The paradigm model: Causal Conditions $\rightarrow$ Phenomenon $\rightarrow$ Context $\rightarrow$ Intervening Conditions $\rightarrow$ Action/Interaction Strategies $\rightarrow$ Consequences

Explanation of the model: Causal Conditions are the events that lead to the development of the phenomenon. The phenomenon is defined as the core category (i.e., the central idea, event or happening). Context refers to the particular set of conditions and intervening conditions, the broader set of conditions, in which the phenomenon is couched. Action/Interaction Strategies refer to the actions and responses that occur as the result of the phenomenon. And finally, the outcomes of these actions and responses are referred to as Consequences.

\section{Findings}

The main story is about the impact of English teacher's referential questions on university students. This impact is defined as constructive, leading to constructive conversation in the language seminars. Conceptual meaning of the word "constructive" can be viewed as effective and creative. The basic potential of intervening conditions of such conversation lies in the fact that students come to realise changes in the atmosphere of the classroom. Four respondents in the research characterise the atmosphere as relaxed, friendly, connected with pleasure and good feelings. "...the person gets rid of the strictly formal feeling that s/he is at school; it seems to me more relaxed and friendly...". Having been influenced by referential questions, the respondents emphasize their subjective preferences of work in the classroom. Two students, being the most active and enthusiastic, appreciate these questions and their effectiveness in conversation. On the other hand, two non-active, passive 
students express their dislike of referential questions - one of them prefers written assignments, in which he is not required to give an immediate response, and the other one simply claims that group work and doing grammatical exercises is on the top of her preferences. Overall, the referential questions are viewed individually. Thus, general referential questions promise smooth procedure in conversation. When the referential question is a kind of specific personal (intimate) question, individual students feel tension and fear to a certain degree. ... sometimes the kind of intimate question can be unpleasing for the questioned student, e.g. when the student's parents have been divorced and s/he should describe the relationships in the family ...".

In direct teacher-student interaction the students normally respond to teacher's questions. Research shows that the striking feature of the student's response is in the transfer into English. The most demanding part of this transfer seems to be the correct form of the response on phonetic, morphological, lexical and syntactic levels."...it is difficult to think quickly, first to think about the content of the response and at the same time to seek the proper grammatical form and words, to create sentence(s) in order to say right what I want to say ...". The topic of the conversation, linguistic competence and personality of a student (especially the student's temperament, mood, physical and mental conditions) determine whether the response is distinguished by its length or shortness. The two eloquent students in the research performed long and meaningful utterances to such extent that the teacher was forced to set limits so that other students could take part in the conversation. "... you know, I tend to speak so much that the teacher has to stop me ...”. In cases when the student is not interested and involved in the topic, lacks linguistic competence and is considered to be shy as well as introverted, then the teacher is compelled to call such student by name, otherwise the student does not show any willingness to take part in the conversation. However, the response of such student is usually expressed in two or three sentences maximum.

Constructive conversation takes place in context of the class, which is characterised by the educational setting (classroom) and people. The class induces functional influence on the consequences of the conversation. Research shows that the functional influence of people is much more important than the setting. Good feelings of students are evoked in the familiar, smaller-sized classroom, highlighted in the kind of informal, non-educational setting (e.g. café, restaurant). Contrary to this, bad feelings are associated with large lecture rooms. The people (teacher, classmates vs. other students) who are present in the class play a crucial part in developing conversation. The teacher-student relationship has a very positive influence on student performance, especially when the teacher is young, connotatively closer in opinions to the student, has a good sense of humour, is liberal and tolerant, and is interested in the student's response. "... our teacher is very nice, she is young; but if we had another teacher, without any sense of humour and tolerance, I wouldn't feel so good and I would certainly be afraid of speaking ...". On the contrary, when the teacher is older, and at the same time aloof and reserved, the student becomes wary and tensed up, and his/her responses are shorter and more concise. The most signifi- cant feature of the classmates category is the length of acquaintanceship with them, their tolerance towards the length, correctness and accuracy of the response, and the number of classmates in the group, which also makes a difference between the positive influence of classmates and the negative attitude of other students (e.g. unfamiliar students from different study groups). “... when we had the first seminar I didn't want to speak at all; those students around me seemed to me strange, I didn't know them ... or, e.g., if we were somewhere in the lecture hall, let's say all 120 first-year students together and I would know only those 12 who were in my study group, I would decide not to show off and hide in the crowd...".

Through constructive conversation in the language seminar, the student gets good opportunities to express his/her subjective opinion and view on the topic, which subsequently leads to the exchange of views and more creative thinking. The fear of not being consistent with views of the rest of the group is a different matter as it can lead to a negative image of the student before the others. "... the problem arises when my opinions don't correspond with the opinions of my colleagues, then I worry about creating a negative image before others ..." In constructive conversation the student realises his/her individual performance in the English language, applies subjective creativity in speech and at the same time demonstrates individual qualities hence developing and improving his/her own communicative competence. "... basically, I practice and improve my speaking skills, I can be imaginative and inventive, I can create my own response...". "... as I know that my English is very good, I love speaking English and showing others my ego...”. Last but not least in the research is the category of creating interpersonal relationships in the class. Since the students listen to each other, give and receive a lot of information about each other as well as the teacher, who also takes part in conversation, students grow closer to each other. "...we manage to know each other better, it can be, in a way, coming closer to each other; we speak about ourselves, express our views and opinions, of course, if we are open and sincere, and the teacher too, s/he can also tell us about herself/himself; it's reciprocal ...".

\section{Conclusion}

Many well-known researchers (M. Long \& Ch. Sato, T. Lynch, T. Pica, J. White \& P. Lightbown, C. Brock, etc.) have investigated and discussed the issue of referential questions in the language classroom. Their predominantly quantitative and quantitative-qualitative studies showed that the distribution of asking the two basic types of questions - display vs. referential was approximately $4: 1$, i.e. display questions outnumbered by far referential ones. Moreover, the researchers highlighted that asking referential questions in the classroom is important because they can trigger longer and syntactically complex answers from students and produce more classroom interaction.

The purpose of the qualitative research carried out in the language seminar classroom was to point out the importance and usefulness of asking referential questions from the point of view of the first - year university students. Having applied the methodology of the grounded theory, it can be claimed that the impact of 
English teacher's referential questions on students is viewed as constructive, leading to constructive conversation in the language seminar. This conversation takes place in a class, which is characterised by educational setting (classroom) and people (a teacher, students).The action/interaction part of this constructive conversation lies in a student's answer/response which is given to a particular referential question. The striking feature of the student's response is in the transfer into English. Both causal (topic of the conversation, linguistic competence and personality of a student) and intervening conditions (subjective preferences of a student, student's individual perception of referential questions and atmosphere) set influence on the procedure of the constructive conversation in the language seminar. To conclude, the most significant consequences of such conversation are: expressing the student's subjective opinion; demonstrating his/her individual performance in the English language; developing and improving his/her communicative competence; and creating interpersonal relationships in the classroom. Further research is necessary for verification and deeper analysis of all the factors which influence this conversation.

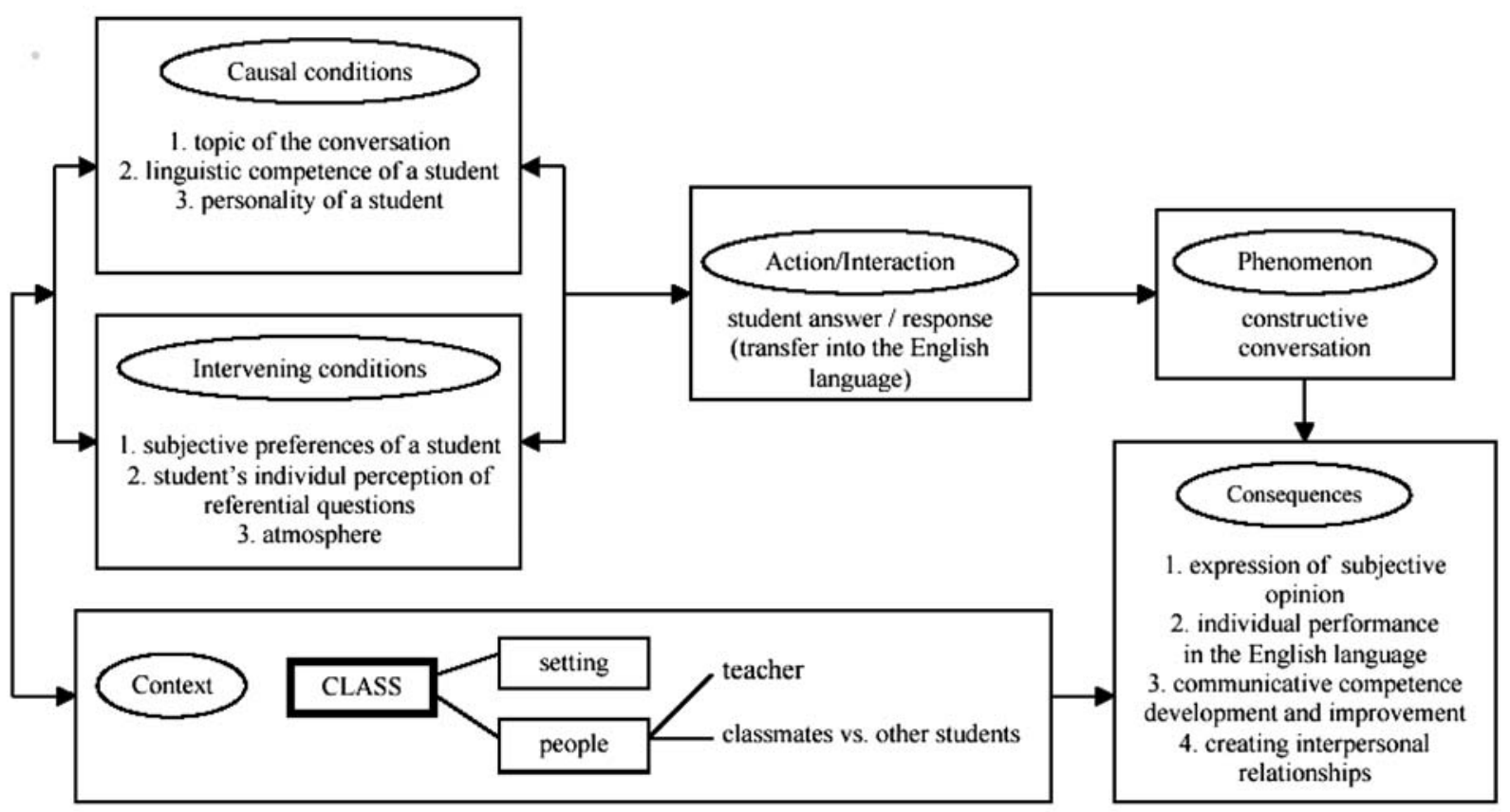

Fig. 1 Diagram of the development of constructive conversation

\section{References}

[1] BROWN, H. D.: Teaching by principles. An Interactive Approach to Language Pedagogy. New York: Pearson Education, 2001

[2] LONG, M., SATO, C.: Classroom Foreigner Talk Discourse: Forms and Functions of Teachers' Questions. In Herert Seliger \& Michael Long (Eds.), Classroom oriented research in second language acquisition, Rowley: Newbury House Publishers, 1983, pp. 268-286

[3] PICA, T.: Lecture on November 1, 1999. In Cheryl Wey-yu Chen. Teachers' Questions in Language Classrooms. [online], [cited $2007-$ 07-30] http://english.nccu.edu.tw/academic/ doc/Paper/

[4] BROCK, C.: The Effects of Referential Questions on ESL Classroom Discourse. TESOL Quarterly, Vol. 20, No. 1, March 1986, pp. 47-59

[5] LYNCH, T.: Communication in the language classroom. Oxford: Oxford University Press, 1996

[6] PANDIT, N. The Creation of Theory: A Recent Application of the Grounded Theory Method. [online], [cited 2007-07-31], http://www.nova.edu/ssss/QR/QR2-4/pandit.html 